\title{
Estimating the persistence of party cue influence in a panel survey experiment ${ }^{1}$
}

\author{
Ben M. Tappin ${ }^{2} \&$ Luke B. Hewitt ${ }^{2}$ \\ Forthcoming at Journal of Experimental Political Science
}

\begin{abstract}
Perhaps hundreds of survey experiments have shown that political party cues influence people's policy opinions. However, we know little about the persistence of this influence: is it a transient priming effect, dissipating moments after the survey is over; or does influence persist for longer, indicating learning? We report the results of a panel survey experiment in which U.S. adults were randomly exposed to party cues on five contemporary U.S. policy issues in an initial survey, and gave their opinions. A follow-up survey three days later polled their opinions again. We find that the influence of the party cues persists at $\sim 50 \%$ its original magnitude at follow-up. Notably, our design rules out that people simply remembered how they previously answered. Our findings have implications for understanding the scope and mechanism of party cue influence as it occurs in the real world, and provide a benchmark for future research on this topic.
\end{abstract}

\footnotetext{
${ }^{1} \mathrm{We}$ are grateful to David Rand for funding this research. We would also like to thank Bert Bakker and three anonymous reviewers for their helpful comments during the review process. The appendix, data and analysis code for this paper are available online https://osf.io/t7qdr/. ${ }^{2}$ Massachusetts Institute of Technology. Corresponding author email benmtappin@googlemail.com.
} 
To what extent do political parties influence citizens' opinions about policy issues? The answer to this question has implications for our understanding of citizens' political psychology and participation, and, by extension, for descriptive and normative theories of democracy. It is thus unsurprising that a large body of work has been dedicated to studying the influence of political parties on citizens' policy opinions (for recent reviews, see (Bullock 2011, 2020; Tappin 2020)). The results of this work speak in a clear voice: When parties take positions on issues, citizens update their opinions toward the positions of preferred parties, and away from those of dispreferred parties on average.

Supporting this conclusion are dozens, and perhaps even hundreds, of studies using survey-experimental designs in which exposure to the policy positions of parties is randomized. These survey experiments avoid the challenges to causal inference that arise when studying observations of party position-taking in the real world (Slothuus and Bisgaard 2020). For example, among other challenges, it is often difficult to completely rule out unobserved confounders — variables that affect both the party position and citizens' opinions, inducing a spurious, non-causal association between the two-as well as reverse causation; the possibility that party position-taking was influenced by citizens' existing (or projected) opinions, rather than the other way around (Zaller 2012).

The strengths and weaknesses of survey experiments are well documented (Barabas and Jerit 2010; Gaines, Kuklinski, and Quirk 2007; Mullinix et al. 2015). In particular, while they allow for clearer causal inferences, this can come at a cost to external validity; the extent to which the results can be accurately generalized to explain or predict observations in other contexts, such as the dynamics of public opinion observed in the real world. In this respect, one of the foremost limitations of the prototypical survey experiment may be its transience, given that "background information, experimental treatments, and outcomes [are recorded] all in the space of a few minutes" (Coppock 2021, Ch.6). For example, if opinion change observed 
in survey experiments dissipates as soon as the survey is over, scholars might reasonably ask “in what real-world scenario would such effect[s] matter?" (Gaines, Kuklinski, and Quirk 2007), and conclude that the effects are mostly laboratory curiosities (Coppock 2021, Ch.6).

Survey experiments on the influence of party cues do not escape these concerns. In the overwhelming majority of such survey experiments, policy opinions are measured in the same survey as the party cue treatment is delivered; in many cases, even on the same survey page as the party cue treatment. Indeed, we are aware of just one party cues survey experiment in which respondent's policy opinions were collected in a later survey conducted sometime after the initial survey (Coppock 2021, Ch. 6, Study 6). As a result, the question of whether and to what extent party cue effects persist beyond the typical survey treatment remains unclear. The answer to this question has implications for our understanding of the scope, and likely mechanism, of party influence as it occurs in the real world.

For example, whether party cues constitute powerful or marginal influences on citizens' policy opinions is a topic of long-standing interest. However, it has been difficult to draw general conclusions about the magnitude of party cue influence because of the substantial variation between different studies' estimates (Bullock 2011, 2020; Tappin 2020). Studying the extent to which party cue influence persists may provide new insight into whether party cues constitute powerful or marginal influences on citizens' policy opinions. If large initial effects mostly dissipate 10 minutes after the survey has ended, this puts pause to the inference that party cues are powerful shapers of citizens' policy opinions; an inference that could have otherwise readily been made on the basis of the large initial effects.

Furthermore, identifying the persistence of party cue effects can help to advance scientific understanding of the relative influence of party cues versus substantive policy information on people's opinion formation (Bullock 2011; Cohen 2003). In particular, while studies estimating the persistence of party cue effects are generally lacking, there are numerous 
studies that estimate the persistence of substantive information. Kuziemko and colleagues (2015), for example, conducted survey experiments in which they exposed people to detailed, interactive information regarding U.S. income inequality and measured people's attitudes toward inequality and preferences for redistribution. They found that some effects of the information persisted at similar magnitudes one month later. Coppock and colleagues (2018) conducted survey experiments in which they exposed people to lengthy, newspaper opinioneditorials on a variety of policy issues, finding that initial changes in attitudes persisted up to one month later at around 50\% the magnitude. These and numerous other studies suggest that opinion change due to information treatments generally persists, sometimes for a considerable length of time (Coppock 2021, Ch.6). In contrast, perhaps party cue effects much more quickly dissipate, despite sometimes causing a larger initial change in opinions than substantive information. This notion is suggested by prominent theoretical accounts of party cue effects, which posit that cues are processed "heuristically" rather than systematically (Bullock 2020; Mondak 1993; Tappin and McKay 2021); thus, their influence may wane faster than that of substantive information. If this is the case, it would paint a more nuanced picture of the relative influence of party cues versus substantive policy information on people's opinion formation.

Finally, studying the persistence of party cue effects in survey experiments can also offer insight into the likely mechanism by which party cues shape public opinion in the real world. For example, suppose that influence due to a single exposure is typically fleeting, dissipating soon after the survey has ended. This would imply that, for real-world party cues to meaningfully shape public opinion as measured in polls and at the ballot box, exposure may have to be repeated, or be delivered via specific channels such as trusted news media or one's social network; channels that may enhance persistence. Subsequent survey experiments could investigate such ideas. Before then, however, comes the task of estimating persistence of party cue influence in the prototypical survey experiment. We take up that task here. 


\section{Our experiment}

We conduct a panel survey experiment in which, during an initial survey, American adults are randomly exposed to party cues (or not) on five contemporary U.S. policy issues, and we collect their opinions on the issues. Respondents are then re-contacted three days later, at which point we collect their opinions on the five policy issues again. This is a standard panel survey experiment design for estimating the persistence of treatment effects. However, in the spirit of enhancing the external validity of our persistence estimates, we also include a slight modification of this standard design by randomizing whether respondents give their opinions in the initial survey or not (irrespective of this randomization, all respondents give their opinions in the follow-up survey). The logic of this design modification is that, when people are exposed to party cues in the real world, they are typically not required to report their opinion on the policy in question at the same time. Rather, their opinion may be polled at a later time; in conversation with friends, while posting on social media, and so on. Asking survey respondents to report their opinions immediately post-treatment may "crystallize" the treatment effect, boosting its persistence, but in a manner that does not reflect the dynamic between real-world party cues and opinion formation. Concretely, we thus expected that respondents who report opinions at both initial and follow-up survey (the standard design) would exhibit stronger persistence than those who only report opinions at follow-up.

To preview our results, we find that party cue influence persists at approximately $50 \%$ magnitude three days later. Contrary to our expectations, however, we find no evidence that persistence is weaker among those who only report opinions at follow-up.

\section{Methods}

\section{Design}


Respondents entering the survey were informed that this was a two-part survey, and that people who completed both parts would receive an additional $10 \%$ bonus payment. After providing informed consent by clicking through the consent form, they answered pre-treatment demographics questions before proceeding to the policy rating segment of the survey. In the policy rating segment, respondents saw five contemporary U.S. policy issues in randomized order (one per survey page); and, on each issue, were randomly assigned to receive either a party cue or no cue. The issue questions were

1. Should an in-state sales tax apply to online purchases of in-state buyers from out-ofstate sellers?

2. Should pension payments be increased for retired government workers?

3. Should the Federal Reserve Bank be audited by Congress?

4. Should the U.S. increase or decrease foreign aid spending?

5. Do you support a single-payer healthcare system?

These issue questions and their corresponding party cues were sourced from the website www.isidewith.com, an online encyclopedia that collates and provides Americans with information about the policy positions of dozens of political candidates and leaders. The encyclopedia professes to be non-partisan and not affiliated with any candidate, political party, corporate sponsors, investors, or interest groups. These issues were chosen on the basis of recent research which found at least moderately-sized party cue effects on the issues when opinions were collected immediately post-treatment (Tappin 2020). Part of our rationale for selecting the issues this way was to maximize the immediate post-treatment effects, thereby facilitating our chances of statistically detecting persistence at follow-up. The party cues consisted in the positions of Donald Trump and Barack Obama on each issue, as documented 
by the analysts at isidewith. For all issues, the positions of Trump and Obama were always in opposition, and respondents assigned to the party cue treatment always saw both leaders' positions. The delivery of the party cue treatment is illustrated in Figure 1. There was no deception used in the party cue treatments or survey as a whole, negating the need to debrief respondents. The experiment reported in this article is under the approval of the Committee on the Use of Humans as Experimental Subjects at Massachusetts Institute of Technology.

Prior to starting the policy rating segment, respondents were randomly assigned to either report their policy opinions at both initial and follow-up surveys - the standard persistence design — or only at follow-up. Respondents in the latter condition were not asked to give their opinion on any of the policy issues in the initial survey; whereas, those in the former condition were asked to do so. Three days after the initial survey was fielded, respondents who completed the survey were re-contacted and invited to complete the followup survey. We closed the follow-up survey after it had been in the field for two days. In the follow-up survey, respondents saw the five policy issues again (in randomized order) and all respondents were asked for their opinion on each issue. In both initial and follow-up surveys, opinions were given on a 7-point Likert scale, anchored from "Definitely No" (1) to "Definitely Yes" (7) for issue questions 1, 2, 3 and 5; and from "Definitely Decrease" (1) to "Definitely Increase" (7) for question 4. The full survey instrument is available online https://osf.io/t7qdr/.

For our analysis, we recode policy opinions such that higher values indicate greater agreement with the in-party cue. For example, a Democrat respondent who strongly supported the "Bank audit" policy—originally a score of 7 on the opinion scale—would receive a score of 1 , since the in-party cue (Obama's position) is to oppose this policy. In contrast, a score of 7 from a Republican respondent would retain its original coding, since the in-party cue (Trump's position) is to support the policy. (And vice versa for issues where the cue direction is reversed.) Accordingly, the expected sign of the party cue treatment effect is positive for all 
respondents and issues. (We report results separately for Democrats and Republicans in the Appendix.) Respondents' partisanship is determined by their party preference using a pretreatment party ID question. Those who identified as Independents were asked who they would prefer to be in power in the U.S. - the Democratic or Republican Party-in a binary forcedchoice question, and this is treated as their party preference for the outcome re-coding. (We also analyze the data excluding Independents in the Appendix; the results are the same).

\section{Do you support a single-payer healthcare system?}

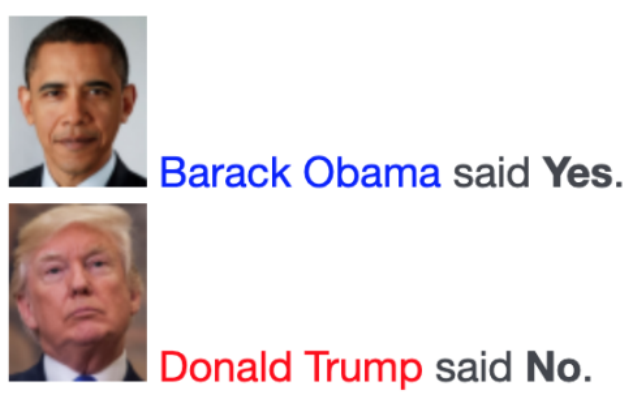

Figure 1. Illustration of the party cue treatment in our design.

\section{Sample}

We aimed to recruit 850 American adults from the survey provider Prolific, which would correspond to a total of 4,250 observations given our design $(850 * 5)$. A total of 879 respondents started the initial survey; 854 completed the initial survey; and 773 completed both the initial and follow-up surveys. In the Appendix, we report the results of a frequentist sensitivity power analysis, illustrating the size of party cue effects we can reliability detect with our sample and design. Under reasonable assumptions about the data generating parameters, this analysis 
indicates that our sample and design can detect a standardized party cue ATE of between 0.15 and 0.20 with $>80 \%$ power. That is, an effect size conventionally considered small.

Samples recruited via Prolific are convenience samples, not representative of the general U.S. population. For example, they tend to skew more educated and Democrat. However, a growing body of evidence suggests this does not particularly compromise the generalizability of our estimates: formal comparisons between treatment effects estimated in convenience samples versus those in national samples indicate the two often correspond quite closely (Coppock 2019; Mullinix et al. 2015). The initial survey was fielded Jan. 14th, 2021.

\section{Attrition}

A total of 106 respondents dropped out of the panel survey (879-773). Of these losses, 14 occurred pre-treatment, and 11 during the post-treatment policy rating segment of the initial (t0) survey. The remainder were lost between the two survey waves (i.e., panel attrition), with 81 of 854 respondents ( $9 \%$ ) failing to complete the follow-up (t1) survey after completing the initial survey; making for a sample return rate of approximately $91 \%(\mathrm{~N}=773)$. All panel attrition is by definition post-treatment in our design. While low, this rate of attrition is not negligible, and so we follow others in only analyzing data from respondents who completed both survey waves, to allow for more valid comparisons between treatment effects estimated at initial vs. follow-up surveys (Coppock 2021, Ch.6). However, this approach assumes that all post-treatment attrition is non-differential between treatment and control groups (if dropout is differential by treatment, it could introduce bias into our estimates). We examine this assumption in detail in the Appendix, but provide a brief summary here.

In the Appendix, we report the results of models predicting post-treatment dropout as a function of treatment assignment to party cue (for each issue) or opinion-measurement condition: $\mathrm{t} 0$ - $\mathrm{t} 1$ vs. $\mathrm{t} 1$-only ( $\mathrm{t} 0$ - $\mathrm{t} 1$ denotes the condition in which respondents' opinions were 
measured at both initial and follow-up surveys, while t1-only denotes the condition in which their opinions were only measured at follow-up). There is no evidence of differential dropout by opinion-measurement condition: assignment to measurement condition does not predict post-treatment dropout $(\mathrm{p}>.05)$. In contrast, there is some evidence of differential dropout by party cue treatment on the "foreign aid" issue: respondents assigned to the control (no cue) condition on this issue were more likely to dropout than those assigned the party cue $(p<.001)$. In terms of raw numbers, of the 92 respondents who dropped out post-treatment, 63 were in the control (no cue) group on the foreign aid issue, and 29 were in the treatment (party cue) group. While this may well be statistical noise, we take several steps to mitigate the risk of bias in our treatment estimates at initial and follow-up surveys. In particular, as well as our primary models reported below, we fit additional models in the Appendix in which we (a) adjust for a range of pre-treatment covariates that are (mildly) correlated with our outcome variable and (b) exclude the foreign aid issue. The results of these models are substantively identical to those reported below, obviating serious concerns about bias.

\section{Results}

Panels A and B in Figure 2 show the raw data from the initial survey (t0) and follow-up survey (t1), respectively. The $\mathrm{x}$ axis indicates the between-subjects' randomization to conditions in which respondents either reported their policy opinions at both t0 and $\mathrm{t} 1$ - the standard persistence design — or only at t1. The outcome variable, policy opinion, is on the y axis and is coded such that higher values equal more party-consistent opinions (see Methods). As indicated by the raw data in Figure 2A, in the initial survey respondents updated their opinions toward the in-party cue on average when this was learned. The raw effect size is approximately half a Likert-scale point, consistent with previous research (Bullock 2011; Tappin 2020). Figure $2 \mathrm{~B}$ shows the data from the follow-up survey, which suggest the influence of the party 
cue is somewhat attenuated, but not eliminated, by follow-up. Interestingly, and inconsistent with our expectation, the influence of the party cue at follow-up does not appear to be larger in the $\mathrm{t} 0$ - $\mathrm{t} 1$ measurement group (standard persistence design) compared to the t1-only group. If anything, the raw data suggest that party cue influence at follow-up is smaller in the t0-t1 measurement group.

In Figure 2C, we show the estimates in standardized units. The left-most estimate is the average treatment effect of the party cue at $\mathrm{t} 0$. We obtain this estimate by fitting a Bayesian multilevel model to the observation-level data at t0 with a dummy variable for party cue treatment. The model allows the ATE of the party cue to vary across the five policy issues, as well as across respondents. The prior distributions on the model parameters are vague and weakly-informative, allowing the data to "speak for itself." The model is fitted using Stan via the package brms (Bürkner 2017) in the statistical software $\mathrm{R}$, and is written formally in the Appendix along with greater detail regarding model specification and diagnostics.

The middle estimate in Figure $2 \mathrm{C}$ is the ATE of the party cue at $\mathrm{t} 1$, averaged across $\mathrm{t} 0$ t1 and t1-only measurement conditions. Finally, the right-most estimate is the difference between ATEs at $\mathrm{t} 1$ in the $\mathrm{t} 0$-t 1 vs. $\mathrm{t} 1$-only condition, and is coded such that positive values imply that the ATE in the t1-only condition is larger. The middle- and right-most estimates are obtained by fitting a Bayesian multilevel model to the observation-level data at $\mathrm{t}$, with dummy variables for party cue treatment, t1-only condition, and their interaction term. All three parameters are allowed to vary across the five policy issues; and the party cue ATE parameter across respondents. As before, the prior distributions on all parameters are vague and weaklyinformative. (Further details are in the Appendix.) 
A

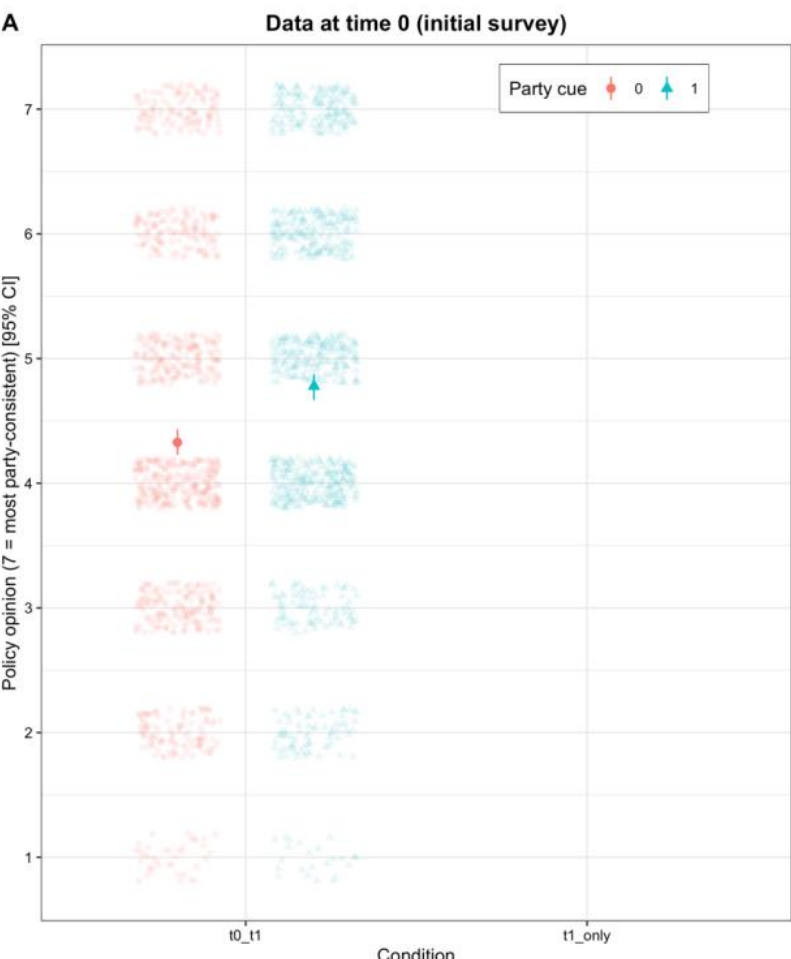

B

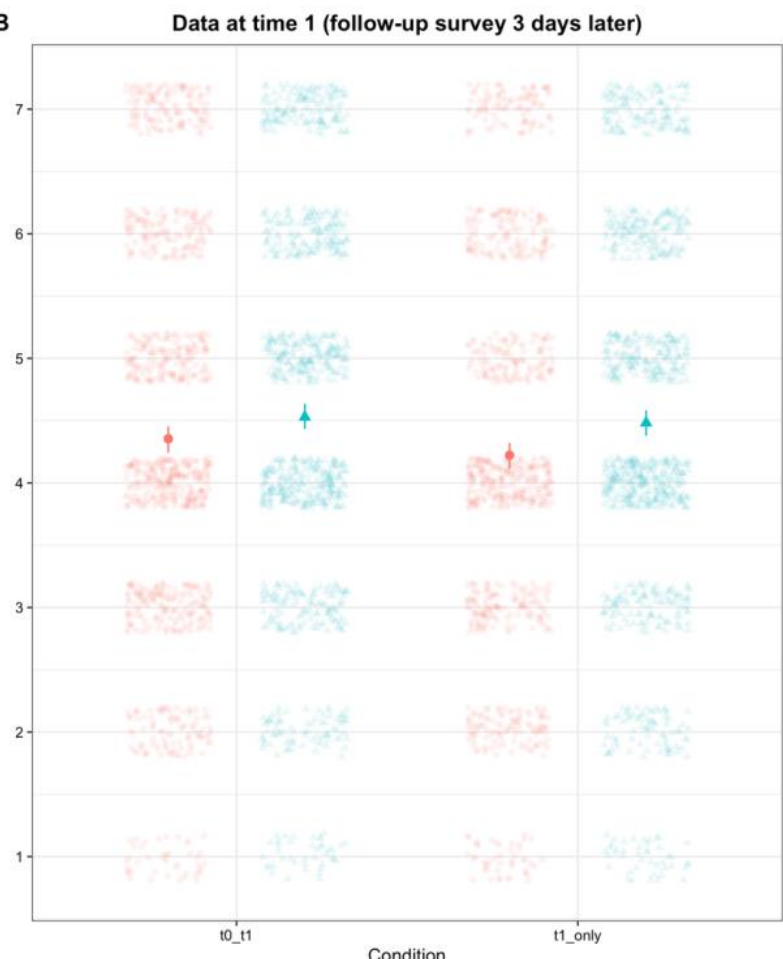

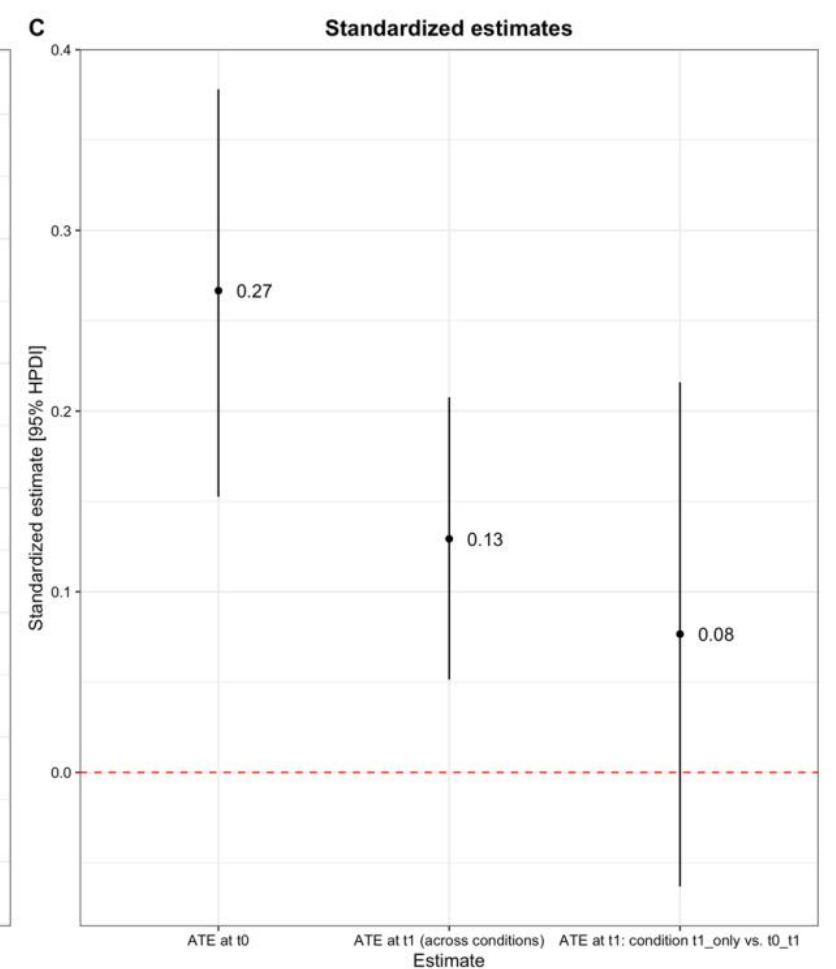

Figure 2. Data and aggregate results from the panel survey experiment. Panel A shows the raw data from the initial survey (t0). Panel B shows the raw data from the follow-up survey (t1). The raw data have slight vertical jitter to aid visibility. The y axis in panels A and B is the Likert scale response, re-coded so that higher values equal policy opinions that are more consistent with the in-party cue (see Methods). The data are colored according to the control (no cue) and party cue conditions, and the means and 95\% confidence intervals are overlaid. The $\mathrm{x}$ axis in panels A and B splits the data according to whether respondents reported their policy opinions at both $\mathrm{t} 0$ and $\mathrm{t} 1$ (the standard persistence design) or only at $\mathrm{t} 1$. Panel $\mathrm{C}$ shows the estimates in standardized units from the Bayesian multilevel models fitted to the raw data. The error bars are $95 \%$ highest posterior density intervals. From left to right in panel $\mathrm{C}$, the $\mathrm{x}$ axis shows the ATE at t0, the ATE at t1 (averaged across opinion-measurement conditions) and the difference between the t1 ATE in the two opinion-measurement conditions. 
As implied by the raw data, the ATE of the party cue at t0 is in clear evidence and is bounded convincingly away from zero - indicated by the 0.95 intervals. The ATE of the party cue at t1, 3 days later, is approximately 50\% the magnitude, and is also bounded away from zero. ${ }^{3}$ Finally, inconsistent with our expectations, the sign of the difference-in-difference estimate is positive (right-most estimate in Figure 2C). This implies that the party cue ATE at t1 was on average $~ 0.08$ SDs larger in the t1-only vs. t0-t1 opinion-measurement condition, though the interval overlaps comfortably with zero. In other words, respondents who reported their opinions in both survey waves did not exhibit greater persistence than respondents who only reported their opinions at follow-up. Thus, we find little evidence in these data that the standard persistence design — measuring opinions immediately post-treatment and then again at follow-up - crystallizes the treatment effect, thereby inflating estimates of persistence relative to measurement at follow-up only. Further tests of this possibility are nevertheless required to confidently rule it out.

Our design also affords a first exploration of whether and how persistence estimates vary across different policy issues. For example, perhaps people are more likely to learn the positions of parties on issues that are more important or salient (e.g., single-payer healthcare) vs. less so (a new in-state sales tax), thereby enhancing persistence. Figure 3 shows the estimates for each policy issue in our sample. The estimates are computed from the full posterior distributions of the models fitted to obtain the aggregate results, not the result of fitting new or separate models for every issue. Thus, the issue-level estimates are mildly regularized, improving their out-of-sample accuracy on average (McElreath 2020). We observe little evidence of heterogeneity in any of the estimates across policy issues: the influence of the

\footnotetext{
${ }^{3}$ We can also formally estimate a ratio of the party cue ATE at $\mathrm{t} 1 \mathrm{vs}$. 0 ; that is, the "persistence estimate" itself (Coppock 2021, Ch. 6). Doing so, we find that the point-estimated persistence ratio is 0.48 , with a $95 \%$ highest posterior density interval of $[0.10,0.84]$. The details of this analysis are reported in the Appendix.
} 
party cue persists 3 days later at approximately 50\% magnitude for all the issues in our sample. The data and code necessary to reproduce the results in this paper are available online: https://osf.io/t7qdr/.

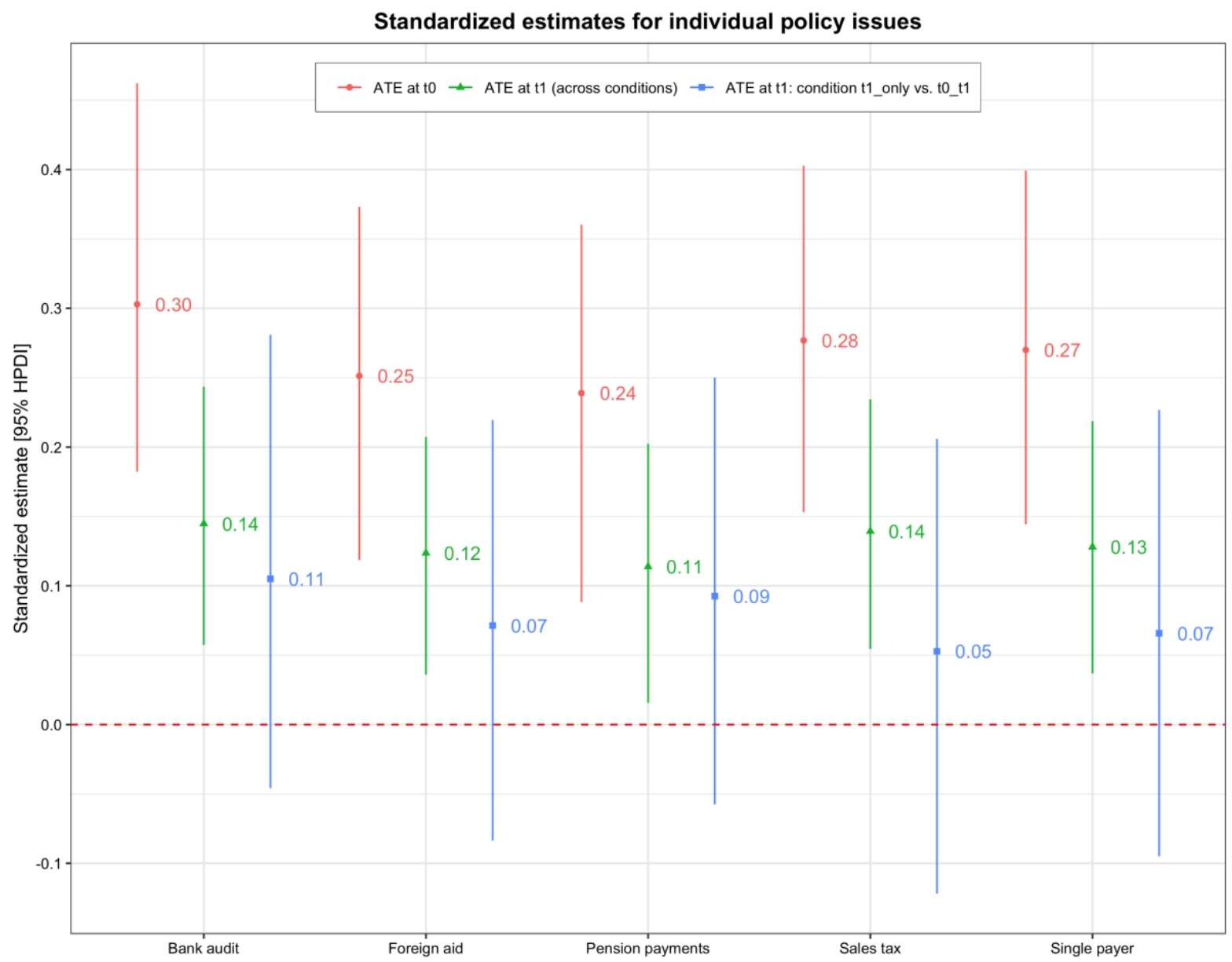

Figure 3. Issue-level estimates from the panel survey experiment. 


\section{Conclusion}

The results of our panel survey experiment suggest that party cue influence observed in survey experiments persists beyond the confines of the survey experiment; by our estimates, remaining at approximately $50 \%$ its original magnitude three days later. This finding is more compelling for the fact that we also observed it in our t1-only measurement condition, in which respondents did not give their opinion (nor see the opinion scale) at the time they were initially exposed to the party cues. Had we implemented only the standard persistence design ( $\mathrm{t} 0$ - $\mathrm{t} 1$ measurement) and observed our results, a reasonable explanation for the observed persistence would be that some respondents simply remembered how they answered at t 0 and reproduced this answer at t1. Our design and results largely negate this explanation. Thus, our results largely negate the concern that party cue influence regularly observed in survey experiments simply reflects highly transient priming or a mere response bias, rendering the phenomenon a laboratory curiosity only (Coppock 2021, Ch.6; Gaines, Kuklinski, and Quirk 2007).

Despite the large number of survey experiments investigating the influence of party cues (Bullock 2020; Tappin 2020), there is a lack of evidence that can speak to whether and how this influence persists. The one exception of which we are aware is Study 6 reported in Coppock (2021, Ch.6). Replicating a party cues survey experiment conducted by Nicholson (2012), Coppock finds that an initial ATE of $\sim 0.13$ SDs completely disappears by follow-up ten days later. This discrepancy with our persistence result could be due to various factors. For example, the initial ATE is considerably weaker than that observed in our experiment, which could be due to differences in how the party cue treatment was operationalized. We included thumbnail pictures of the party leaders' faces in our treatment, for instance, whereas Coppock/Nicholson did not. Furthermore, it is plausible that Donald Trump is a more polarizing figure than John McCain. The upshot is that perhaps larger initial party cue effects persist for longer, explaining our discrepant results (but see Coppock 2021, Ch. 6 for indirect 
evidence against this hypothesis). Another obvious explanation is that we measured persistence after three days, whereas Coppock measured it after ten. In theory, our results could be entirely consistent if party cue effects generally persist up to and beyond three days, but disappear by the tenth day post-treatment.

Therefore, taken together these estimates suggest that detectable persistence of party cue influence in survey experiments sits somewhere between three and ten days' posttreatment, with the caveat that it could well be longer. This provides a baseline for future work to build upon when investigating heterogeneity in, and predictors of, the persistence of party cue effects. For example, nascent research on the persistence of news framing effects suggests that an individual's political knowledge is a reliable predictor of persistence there (Lecheler and Vreese 2016). Given the long-standing interest in political knowledge as a moderator of (immediate) party cue effects (Bullock 2020), a natural next step is to ask whether political knowledge also predicts the persistence of these effects.

What implications do our results have for understanding the scope, and likely mechanism, of party influence as it occurs in the real world? First, that a single, brief exposure to a party cue detectably influenced opinions three days later speaks to the potential power of party cues in shaping public opinion. It is likely that even people who do not follow politics closely are occasionally exposed to party cues on various issues; our results imply these exposures may well exert meaningful influence, i.e., that persists beyond a day or two (see also Weeks, Lane, and Hahn 2021). Furthermore, party cues are easily disseminated-and increasingly so - to large numbers of people via social and partisan media, meaning that shortterm persistence may be "topped-up" regularly, and with little effort on the part of consumers. By contrast, for substantive policy information to influence opinions often requires significantly more effort in the sense that people must actively consume (e.g., read or otherwise closely attend to) such information. 
On the other hand, however, evidence regarding the persistence of information effects suggests these effects tend to persist for longer than three days, sometimes much longer (Coppock 2021, Ch.6; Coppock, Ekins, and Kirby 2018; Kuziemko et al. 2015). This offers additional nuance to scientific understanding of the relative influence of party cues versus policy information on people's opinion formation (Bullock 2011; Cohen 2003). Specifically, while party cues may exert strong initial influence on a large number of people, this influence may be more short-lived than that exerted by substantive policy information; but the latter plausibly reaches fewer numbers of people in total. Future work can more systematically investigate this notion by estimating the persistence of party cue and policy information effects within the same experiment and on the same policy issues. 


\section{References}

Barabas, Jason, and Jennifer Jerit. 2010. “Are Survey Experiments Externally Valid?" American Political Science Review 104(2): 226-42.

Bullock, John G. 2011. "Elite Influence on Public Opinion in an Informed Electorate." American Political Science Review 105(3): 496-515.

. 2020. "Party Cues." The Oxford Handbook of Electoral Persuasion. https://www.oxfordhandbooks.com/view/10.1093/oxfordhb/9780190860806.001.000 1/oxfordhb-9780190860806-e-2 (February 18, 2020).

Bürkner, Paul-Christian. 2017. "Brms: An R Package for Bayesian Multilevel Models Using Stan." Journal of Statistical Software 80(1): 1-28.

Cohen, Geoffrey L. 2003. "Party Over Policy: The Dominating Impact of Group Influence on Political Beliefs." Journal of Personality and Social Psychology 85(5): 808-22.

Coppock, Alexander. 2019. "Generalizing from Survey Experiments Conducted on Mechanical Turk: A Replication Approach." Political Science Research and Methods 7(3): 613-28.

- 2021. Persuasion in Parallel. Chicago: University of Chicago Press.

Coppock, Alexander, Emily Ekins, and David Kirby. 2018. "The Long-Lasting Effects of Newspaper Op-Eds on Public Opinion." Quarterly Journal of Political Science 13(1): 59-87.

Gaines, Brian J., James H. Kuklinski, and Paul J. Quirk. 2007. "The Logic of the Survey Experiment Reexamined." Political Analysis 15(1): 1-20.

Kuziemko, Ilyana, Michael I. Norton, Emmanuel Saez, and Stefanie Stantcheva. 2015. "How Elastic Are Preferences for Redistribution? Evidence from Randomized Survey Experiments." American Economic Review 105(4): 1478-1508.

Lecheler, Sophie, and Claes H. de Vreese. 2016. "How Long Do News Framing Effects Last? A Systematic Review of Longitudinal Studies." Annals of the International Communication Association 40(1): 3-30.

McElreath, Richard. 2020. Statistical Rethinking: A Bayesian Course with Examples in $R$ and STAN. CRC Press.

Mondak, Jeffery J. 1993. "Public Opinion and Heuristic Processing of Source Cues." Political Behavior 15(2): 167-92.

Mullinix, Kevin J., Thomas J. Leeper, James N. Druckman, and Jeremy Freese. 2015. "The Generalizability of Survey Experiments*." Journal of Experimental Political Science 2(2): 109-38.

Nicholson, Stephen P. 2012. "Polarizing Cues.” American Journal of Political Science 56(1): $52-66$. 
Slothuus, Rune, and Martin Bisgaard. 2020. "How Political Parties Shape Public Opinion in the Real World." American Journal of Political Science. https://onlinelibrary.wiley.com/doi/abs/10.1111/ajps.12550 (November 5, 2020).

Tappin, Ben M. 2020. Estimating the Between-Issue Variation in Party Elite Cue Effects. PsyArXiv. preprint. https://osf.io/p48zb (October 8, 2020).

Tappin, Ben M., and Ryan McKay. 2021. "Estimating the Causal Effects of Cognitive Effort and Policy Information on Party Cue Influence." https://psyarxiv.com/tdk3y/ (February 14, 2021).

Weeks, Brian E., Daniel S. Lane, and Lauren B. Hahn. 2021. “Online Incidental Exposure to News Can Minimize Interest-Based Political Knowledge Gaps: Evidence from Two U.S. Elections." The International Journal of Press/Politics: 1940161221991550.

Zaller, John R. 2012. "What Nature and Origins Leaves Out." Critical Review 24(4): 569642. 